\title{
Cultural Conflict and Merger Failure: An Experimental Approach
}

\author{
Roberto A. Weber • Colin F. Camerer \\ Department of Social and Decision Sciences, Carnegie Mellon University, Pittsburgh, Pennsylvania 15213 \\ Division of Humanities and Social Sciences 228-77, California Institute of Technology, Pasadena, California 91125 \\ rweber@andrew.cmu.edu・camerer@hss.caltech.edu
}

W e use laboratory experiments to explore merger failure due to conflicting organizational cultures. We introduce a laboratory paradigm for studying organizational culture that captures several key elements of the phenomenon. In our experiments, we allow subjects in "firms" to develop a culture, and then merge two firms. As expected, performance decreases following the merging of two laboratory firms. In addition, subjects overestimate the performance of the merged firm and attribute the decrease in performance to members of the other firm rather than to situational difficulties created by conflicting culture.

(Experiments; Organizational Culture; Mergers)

\section{Introduction}

A majority of corporate mergers fail. Failure occurs, on average, in every sense: acquiring firm stock prices tend to slightly fall when mergers are announced; many acquired companies are later sold off; and profitability of the acquired firm is lower after the merger (relative to comparable nonmerged firms). ${ }^{1}$ Participants report a lot of conflict during the merger, resulting in high turnover (Buono et al. 1985, Walsh

\footnotetext{
${ }^{1}$ The most conclusive evidence of lower postmerger profitability comes from studies by Ravenscraft and Scherer (1987, 1989). They use Federal Trade Commission line-of-business data to compare companies' lines of business after they were acquired with a proxy for what their performance would have been without the merger (using comparable control businesses). Operating income as a percentage of assets is lower by 0.03 for the merged target businesses. This is a substantial (and statistically significant) drop because their pretakeover operating income/asset ratio averaged 0.115. Also, McGuckin et al. (1995) provide support for the hypothesis that mergers and acquisitions fail on average, even though their overall interpretation is the opposite (but not clearly supported by their analysis). Specifically, they find that acquisitions decrease productivity and employment at the firm level (even though acquiring firms were highly productive before the acquisition) and this is similarly supported in their initial plant-level analysis. They manage to overturn the productivity result at the plant level only for a subset of plants (those belonging to larger firms).
}

1988). ${ }^{2}$ Participants express disappointment in the mergers' results, and surprise at how disappointed they are. Curiously, widespread merger failure is at odds with the public and media perceptions that mergers are grand things that are almost sure to create enormous business synergies that are good for employees, stockholders, and consumers.

Two examples may help illustrate our ideas about cultural conflict in mergers. In the period leading up to the Daimler-Chrysler merger, both firms were performing quite well (Chrysler was the most profitable American automaker), and there was widespread expectation that the merger would be successful (Cook 1998). People in both organizations expected that their "merger of equals" would allow each unit to benefit from the other's strengths and capabilities. Stockholders in both companies overwhelmingly approved the merger and the stock prices and analyst predictions reflected this optimism. Performance after the merger, however, was entirely different, particularly at the Chrysler division. In the months

\footnotetext{
${ }^{2}$ Walsh and Ellwood (1991) find that the high rate of turnover among management at acquired firms is not related to poor prior performance, indicating that the turnover is not due to the pruning of underperforming management at the acquired firm.
} 
following the merger, the stock price fell by roughly one half since the immediate postmerger high. The Chrysler division, which had been profitable prior to the merger, began losing money shortly afterwards and was expected to continue to do so for several years (CNNMoney, February 26, 2001). In addition, there were significant layoffs at Chrysler following the merger (that had not been anticipated prior to the merger) (CNNMoney, February 29, 2001).

Differences in culture between the two organizations were largely responsible for this failure (Vlasic and Stertz 2000). Operations and management were not successfully integrated as "equals" because of the entirely different ways in which the Germans and Americans operated: while Daimler-Benz's culture stressed a more formal and structured management style, Chrysler favored a more relaxed, freewheeling style (to which it owed a large part of its premerger financial success). In addition, the two units traditionally held entirely different views on important things like pay scales and travel expenses. As a result of these differences and the German unit's increasing dominance, performance and employee satisfaction at Chrysler took a steep downturn. There were large numbers of departures among key Chrysler executives and engineers, while the German unit became increasingly dissatisfied with the performance of the Chrysler division. Chrysler employees, meanwhile, became extremely dissatisfied with what they perceived as the source of their division's problems: Daimler's attempts to take over the entire organization and impose their culture on the whole firm. ${ }^{3}$

While cultural conflict often plays a large role in producing merger failure, it is often neglected when the benefits of a potential merger are examined. For instance, following the announcement of the AOLTimeWarner deal, a front-page Wall Street Journal article (Murray et al. 2000) discussed possible determinants of success or failure for the merger (such as synergies, costs, competitor reaction, and so forth). The only clear discussion of possible cultural conflict is a single paragraph (out of a 60-column-inch article) revealing how the "different personalities" of AOL's

\footnotetext{
${ }^{3}$ For instance, one joke told at Chrysler is: "How do you pronounce DaimlerChrysler? ... 'Daimler' the 'Chrysler' is silent."
}

Steve Case and TimeWarner's Gerald Levin reflect cultural differences between the two firms. A similar article (Jubak 2000) included a single paragraph entitled "What could go wrong with the synergy strategy." Moreover, in these sorts of short, cursory, obligatory discussions of possible cultural conflict, there is rarely discussion of what steps might be taken if there is dramatic conflict.

While culture may seem like a "small thing" when evaluating mergers, compared to product-market and resource synergies, we think the opposite is true because culture is pervasive. It affects how the everyday business of the firm gets done-whether there is shared understanding during meetings and in promotion policy, how priorities are set and whether they are uniformly recognized, whether promises that get made are carried out, whether the merger partners agree on how time should be spent, and so forth.

This paper introduces a simple experimental paradigm to explore cultural conflict as a possible cause of merger failure. The guiding hypothesis is that an important component of failure is conflict between the merging firms' cultural conventions for taking action, and an underestimation by merger partners of how severe, important, and persistent conflicts are. Cultural conventions emerge to make individual firms more efficient by creating a shared understanding that aids communication and action. However, when two joined firms differ in their conventions, this can create a source of conflict and misunderstanding that prevents the merged firm from realizing economic efficiency. We hypothesize that the extent of these conflicts are unexpected because observers focus on tangible aspects of firms' practices (such as technology, capital, and labor costs) and ignore aspects that are more difficult to measure such as culture. This leads to overestimation of the value of a merged firm at the time of the merger.

Our emphasis on cultural conflict is not meant to suggest, of course, that other potential causes of merger failure are not important. Certainly, agency problems, optimism, and hubris may lead top managers to undertake mergers that are bad for shareholders. Also, holding cultural incompatibility aside, conflicts of interest between employees in two merged firms may also harm the merger. For instance, 
employees in each of the two firms may have reasons to prefer maintaining the "old way of doing things"-possibly because of learning costs, inertia, and so on-and may, therefore, intentionally resist adopting the other firms' practices. While we recognize these other potential sources of merger failure, our focus is on one specific cause: differences in culture may simply make it difficult for members of the merged organization to see things in the same way.

Our paradigm also allows us to explore the development of a specific form of tacit knowledge in groups, which we use as a metaphor for culture. The experiments we report in this paper specifically explore what happens when two groups that have independently developed this tacit shared knowledge-which allows them to operate efficiently-need to combine their knowledge and anticipate how difficult it will be to do so.

\section{Organizational Culture}

Organizational culture has received considerable attention from organizational researchers, and substantially less attention from economists. While agreement on a precise definition of the concept has proven difficult, there are a few important elements shared by most definitions. Culture is usually thought of as a general shared social understanding, resulting in commonly held assumptions and views of the world among organizational members (Wilkins and Ouchi 1983, Schall 1983, Rousseau 1990, Schein 1983). Culture is developed in an organization through joint experience, usually over long periods of time. It is useful because it allows an organization's members to coordinate activity tacitly without having to reach agreement explicitly in every instance. Languagein the form of codes, symbols, anecdotes, and rules about appropriate statements-plays an important role in organizational culture, constituting a large part of the shared understanding held by organizational members (Schall 1983, Schein 1983, Cremer 1993).

However, despite agreement that culture is important, it is difficult to precisely measure and study (Schein 1996, Marcoulides and Heck 1993, Rousseau 1990). Researchers have relied on a few different approaches to study culture in organizations (Schein
1990, Rousseau 1990). Much of this research is ethnographic observation of interactions in small numbers of organizations (e.g., Schein 1983, 1990; Barley 1983). While informative and helpful for inspiring theory, the small samples involved in this type of analysis usually make it difficult to draw firm conclusions.

Another approach consists of questionnaires administered to large numbers of members of a few organizations (e.g., Schall 1983, Hofstede et al. 1990, O'Reilly et al. 1991, Chatterjee et al. 1992). The questionnaires are usually designed to measure important elements of culture that can then be compared across firms to draw conclusions about how they differ in culture and how culture affects organizational performance. These studies are useful in that they provide concrete empirical measures of differences between firms on several dimensions related to culture. However, there is often little agreement from one investigation to the next concerning the key elements of culture. Moreover, these studies often have small numbers of independent observations (firms) and the usual concerns in survey research like response bias due to the sample of selected firms not being determined randomly or due to nonresponses being correlated with dependent variables, or the fact that respondents retrospectively recall and evaluate cultural variables.

Culture has received considerably less attention from economists. Kreps (1990) argues that culture presents organizations with a solution to problems resulting from multiple equilibria in which there may be uncertainty about the appropriate behaviorcultural rules are "focal principles" that point to a socially understood solution, limiting the need for explicit communication. Hermalin (2001) summarizes the economic approach to culture and presents a formal model in which culture is an efficiency-improving asset in which firms can invest. Arrow (1974) discusses culture as "codes" developed by organizations to help coordinate activity and points out that these codes are path dependent and may, therefore, differ greatly between firms, even though each is efficient. Lazear (1999) notes the connection between culture and language, particularly in the extent to which it facilitates efficient economic exchange. He defines culture as the shared expectations and patterns of 
behavior among individuals, and uses language as a proxy for measuring culture.

Cremer (1993) builds on Arrow's (1974) concept of codes to define culture in a way similar to what we use in our experiments. He defines culture as "the part of the stock of knowledge that is shared by a substantial portion of the employees of the firm, but not by the general population from which they are drawn" (p. 354). ${ }^{4}$ In Cremer's (1993) model, the organization must respond to outside messages in a coordinated manner, and this is less costly to accomplish when the stock of shared knowledge is greater, because of less time needed for communication. Our experiments can be seen as ways of creating these focal principles and codes in the laboratory, and then measuring their empirical consequences.

Taken together, previous work on organizational culture points to a couple of key elements. One is shared understanding among organizational members, which usually comes about through shared experience (or a process of socialization and handing down of traditions). Culture arises endogenously through this shared experience and is, therefore, path dependent and idiosyncratic. Organizational researchers and economists also agree that this shared understanding is helpful because it allows members of a firm to successfully coordinate activity. Our implementation of culture in the laboratory-similar in many ways to Arrow's (1974) and Cremer's (1993) definition-includes these elements and, therefore, allows us to study culture empirically in a controlled and novel way.

\section{Organizational Culture and Merger Failure}

Many previous studies have touched on aspects of merger failure, though there are none that conclusively document the causal effect of cultural conflict. Most studies simply document success or failure of mergers, without directly addressing differences in culture (e.g., Ravenscraft and Scherer 1987, 1989). Some studies examine the effects on postmerger profitability of product and resource relatedness (Singh

\footnotetext{
${ }^{4}$ This definition is similar to the conceptualization underlying the empirical approach of Hofstede et al. (1990) for identifying culture; see also Barley (1983).
}

and Montgomery 1987, Shelton 1988, Harrison et al. 1991). Most evidence suggests that mergers are more successful when merging firms make related products. Other studies also examine similarities or differences in some areas related to corporate culture, without directly addressing culture (Shanley and Correa 1992).

The studies best able to establish causal effects of conflict and merger failure simply are not conclusive, due to reasons that often arise when working with field surveys and real-world data. One kind of such study typically surveys members of two firms that were merged, asking them to recall aspects of their premerger firm, and then tests the relationship between similarity of premerger firms and subsequent performance (e.g., Chatterjee et al. 1992). Another approach is to rely on existing literature (such as published case studies) that describes previously occurring mergers in detail, coding the content of each article for things like premerger similarity and postmerger synergy realization, and then using these variables to explore the determinants of merger success (e.g., Larsson and Finkelstein 1999). While both of these kinds of studies indicate that postmerger integration and performance are related to the cultural similarity and ability to capitalize on synergies of premerger firms, the results are not quite conclusive because of problems associated with obtaining the ideal data for such a study.

While existing studies provide support for the hypothesis that cultural integration plays an important role in mergers, the causal effects are not clearly determined. This is not because of a flaw in the way the research was conducted, but due to problems that frequently arise when working with realworld data. For instance, in the studies relying on survey responses from employees in the merged firm, these problems include possible response bias, survivorship bias (only people who stuck with a merged firm may return questionnaires), and responses based on possibly biased respondent memory (employees who are a part of a successful merger may recall more similarities between two firms before the merger). Similarly, the studies that code from existing literature may also suffer from selection bias (extremely successful or unsuccessful mergers may be written 
about more frequently and "halo effects" (coding bias that leads synergy realization and organizational integration to be retrospectively coded as closer together than they really are). Of course, both of these kinds of studies also suffer from the impossibility of determining how well firms would have performed if they had not merged and from possibly weak measures of actual postmerger performance. In pointing out these problems, our goal is not to pick on these studies. In fact, we believe they did the best they could, given the limitations of working with real-world data, and that they provide valuable evidence. Our goal is to highlight how difficult it is to have an ideal field study and, hence, how helpful (at the margin) some exploratory experiments might be as a complement to these kinds of studies.

Experiments allow us to control for all these concerns and, therefore, serve as a useful complement to-but not a replacement for-the above studies. This control comes, of course, at a price-reduced generalizability-that springs from the fact that the experiments lack all the features of real-world mergers. However, while experiments often seem to be overly simplified recreations of complicated realworld phenomena, using them can help get a handle on the basic processes underlying these phenomena. ${ }^{5}$ While experiments often give up realism and generalizability, the added control and the ability to precisely measure variables of interest mean that they can be a useful complement to field studies.

\section{Culture in Our Experiments}

In our experiments, culture is a specialized homemade language a pair develops to solve a task. In the task, two subjects with the same set of pictures have to learn to jointly identify a subset of the entire set of pictures. To do this, they must develop tacit shared knowledge, creating a common way to quickly describe the pictures so that a "manager" subject can guide the "employee" to pick the prespecified subset. Two pairs of subjects, or "firms,"

\footnotetext{
${ }^{5}$ See, for instance, Knez and Camerer (1994, 2000), Weber (2000), and Weber et al. (2001). All of these papers use simple experiments to help understand complicated real-world phenomena and processes such as organizational growth, leadership, and transfer of practice.
}

separately develop cultures. Then, the two pairs are "merged." One manager must then describe pictures simultaneously to two employees. Because the manager previously participated only with one of the two employees, we anticipate that the conflict in homemade languages will make it difficult for the manager to get the new employee to pick the correct pictures, and will also slow down the old employee. We, therefore, expect that performance postmerger will be significantly affected by the difference in languages.

The difficulty of cultural integration is well known. Therefore, the expected result that differences in the languages leads to lower performance should not be surprising. The more interesting question-given our hypothesis that participants in a merger typically focus on the gains to be obtained (because of synergies, technology, and so forth) and neglect potential cultural integration difficulties-is whether subjects are aware of the extent of the difficulty associated with merging. If not, they will underestimate the degree of difficulty in resolving cultural conflict. This is measured by having subjects make guesses (for money) about how quickly pictures can be matched in the postmerger phase. Treating these values as subjects' estimates of the value of the merged firm, we can investigate whether the subjects' estimates tend to be more optimistic than the actual performance of the merged firm, implying that underestimation of cultural conflict is one important source of merger failure. $^{6}$

Finally, we also explore subjects' attributions about the sources of possible integration difficulties. Our hypothesis here is that if subjects underestimate the effect of cultural conflict on postmerger integration and performance, then they will also attribute failure to incompetence on the part of others, rather than to differences in perspectives due to cultural differences.

The picture-matching task in our experiments is analogous to situations in which workers can perform any of several possible related activities, but the

\footnotetext{
${ }^{6}$ This overvaluing of mergers is likely to be aggravated in realworld situations by the "winner's curse" (the fact that in auctions for objects of common unknown value, bidders fail to adjust for the fact that high bids reflect the most optimistic guesses about the object value and, statistically, will tend to be higher than the object's true value). See Roll (1986).
} 
correct one depends on some information or knowledge held by managers. Managers have to communicate the information they have to employees quickly and accurately. If a concise natural language to do this does not previousy exist, the organization must develop one to efficiently perform. ${ }^{7}$

The building blocks of our paradigm are minimal analogies to key features of corporate culture. Each pair must learn to jointly react to an external event (the subset of pictures selected by the experimenter) to accomplish a specific task in which the employee has to perform the appropriate actions for that particular event (selecting the correct subset of pictures). Subjects must begin by using elaborate descriptions of the pictures that focus on several features. After several rounds, their descriptions can be honed to a pithy phrase or word that instantly conveys a shared understanding of what is most distinctive about the picture (this is like the development of jargon, distinctive anecdotes, grammars, and so forth-e.g., Schall 1983, Schein 1983).

We should note that we are capturing only one facet of the many complex elements of organizational culture. "Culture" in our experiments is a simplified version of the real-world phenomenon: The groups in our experiments are really developing a form of shared knowledge (what are the identifying aspects of each picture) that allows them to efficiently perform a task. We use this shared knowledge, or language, as a metaphor for broader ideas of culture. ${ }^{8}$ Culture

\footnotetext{
${ }^{7}$ Some similar experiments of this sort have been recently done in game theory (e.g., Blume et al. 1998). They study whether players in sender-receiver games with common interests can develop a homemade language that maps privately observed types into choices of symbols (such as *, \&, and \#). Language formation works well, although it is substantially undermined when there is conflict of interest between the sender's desire to hide their type and the receiver's interest in figuring it out.

${ }^{8}$ The kinds of languages we have in mind are the precise codes that arise in police work, air traffic control, film direction, the military, and so forth. Examples of development and learning of specialized jargon are policemen (figuring out what crime code to use in reporting an incident), lawyers (categorizing cases and applying precedents), filmmaking ("key grip," "best boy"), and doctors (medical jargon). Note in each case how long it takes newcomers to learn the language and how important it is for them to do so. Also interesting are businesses in which words are used
}

is usually defined as a system of values and ideals (what's good), norms (what's expected), and conventions of behavior (how things are done). Agreeing on code names for objects is a huge simplification of all that culture is. But as we stress throughout, it is meant to be just a starting point. Moreover, several researchers have noted the connection between language and culture, specifically noting that a group's language is, perhaps, the most important and most easily directly observable aspect of its culture, because it reflects group members' shared understanding and way of representing the world (Schall 1983, Barley 1983, Hofstede 1984, Cremer 1993, Lazear 1999). What we explore with the merger process is how this tacit shared knowledge is transferred between two groups that need to reconcile disjunctions in their knowledge, and how subjects may be biased in their perceptions of the difficulty of this process.

While it is possible to create something more like a rich organizational culture experimentally, this minimal culture serves as a conservative test of our hypothesis. If even this minimal aspect of culture results in postmerger difficulties in simple firms consisting of only 2 or 3 employees, then we would expect that differences in more elaborate forms of real organizational culture would result in potentially even greater conflict.

We predict that merger failure will occur if the culture each pair develops is path dependent and idiosyncratic. Even if the two firms efficiently perform in the premerger period because of their concise languages, if their languages are different, then postmerger communication among all parties will be difficult. (Indeed, the more deeply ingrained firm-specific language is-and the more efficient the firm-the harder the integration may be.) After a merger, it will take some time to either "train" the new employee to understand the acquiring firm's language or to

to describe visual or sensory images that are not ordinarily translated into language- such as wine tasting, art, and music. (Musicians in recording studios create a rich language to describe, in words, the kinds of sounds they are striving for-calling a drum sound "too crunchy," "too tinny," "cheesy," and so forth. They also use analogy if it is likely to be commonly understood, as in "How about that 'In the Air Tonight' sound?" or "More 'Born in the USA,' please." 
develop a new language shared by all members of the organization.

Note that the "firms" and "mergers" in our experiment are simplified versions of their real-world analogies. Our firms consist of only two or three employees performing one simple task, and the merger consists of taking two companies that consist of one manager and employee each and creating one firm with one manager and two employees. What we are trying to capture is a much more complex process in which many more employees all perform varied and multiple tasks, and in which mergers mean much more complicated combinations of the two firms. As with much experimental research, our goal is simply to use a few key elements to recreate a simplified version of the real world in the laboratory, and use this to help understand the phenomenon in a more controlled environment than the real world.

\section{Methods}

The task in our experiments is based on studies by Clark and Wilkes-Gibbs (1986) and Schober and Clark (1989) to address how shared meaning arises in language. ${ }^{9}$ In the experiments, every subject is presented with the same set of 16 pictures depicting office environments (see Figure 1 for examples). While most of the pictures share some common elements-people, furniture, room characteristics, and so forth-each picture is unique. Among the aspects that vary are the number of people and their characteristics (gender, clothing, ethnicity), physical aspects of the room (high ceilings, objects on walls, furniture), and the actions of the people (conversing with others in the picture, talking on the telephone, working at a computer).

In every round of the experiment, the experimenter indicated 8 of the 16 pictures in a specific order to one subject, in the role of "manager." The manager then described the pictures any way he or she liked to the other subject (the "employee"). The employee had to select the correct 8 pictures, in the same order as indicated by the experimenter to the manager. The manager and employee each earned the same amount of money based on how quickly the task was completed.

${ }^{9}$ See also Krauss et al. (1968) and Fussell and Krauss (1989).
Specifically, the completion time was measured up to the nearest 10 seconds, and both subjects earned $\$ 1$ minus the completion time divided by 300 .

In the first part of each experimental session, two pairs of subjects repeated this task for 20 rounds. Subjects alternated roles (manager or employee) in each round so that they would have experience with both parts of the task and to reduce any possible idiosyncratic effects of a particular manager who might be worse at developing a language. We expected that managers would initially struggle to convey the information to the employees, requiring long, elaborate descriptions before both subjects could agree on a particular picture. However, with experience, they should be able to develop more concise descriptions to refer to each picture and would be able to more quickly perform the task. We expected these descriptions would be idiosyncratic, and would only be effective because of the shared history and understanding that would emerge from repeated interaction with the same coworker.

After allowing the groups 20 rounds of experience with the task so they could develop a shorthand language, the two groups were merged. One firm was randomly selected to take over the other. One subject from the "acquiring" firm was selected to be the manager for the rest of the experiment, and one subject from the other firm was selected to be the "acquired" employee. Therefore, after the merger, there was one firm with one manager and two employees, and the manager and one of the employees had previously been in the same firm.

The acquiring manager then simultaneously performed the same task with 2 employees for an additional 10 rounds. ${ }^{10}$ In this second part of the experiment, the manager simultaneously spoke to both employees, and each employee could complete the task individually of the other employee. Both employees could hear everything the manager said, and the manager was allowed to speak freely

${ }^{10}$ After the merger, the role of manager is fixed, while before the merger, the role of manager alternates between the two members of the firm. While this creates a possible confound (fixed versus alternating role) in the experiment reported here, additional sessions we conducted-in which the role of manager was fixed both pre- and postmerger-produced the same results. 


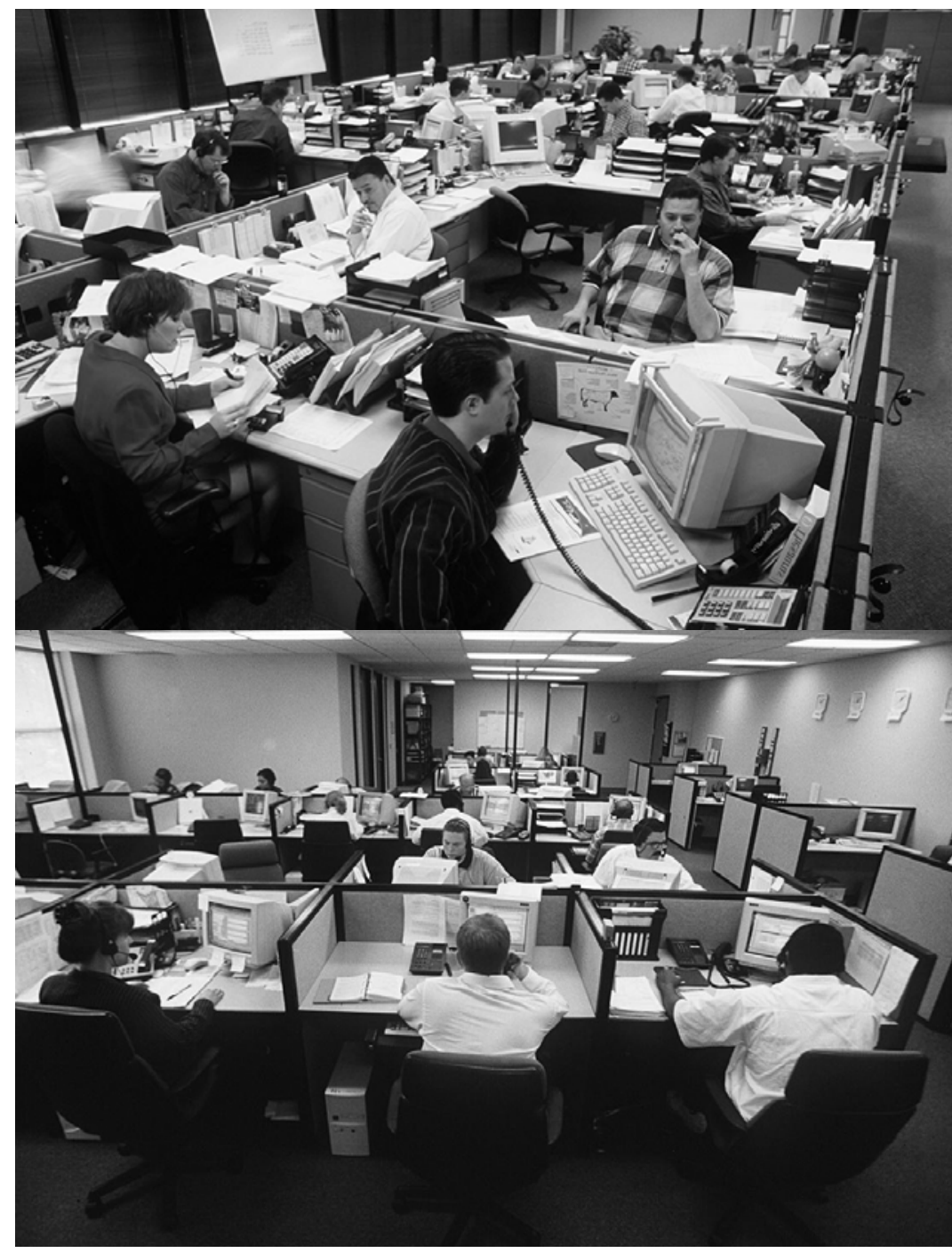

(i.e., the manager could choose to address only one employee-although the other one would overhear). The two employees could finish at different times and receive a different amount in each round for completing the task. The manager received the average of the earnings of both employees.

Subjects were also asked to state a belief about the average time it would take the two postmerger employees to complete the task during the remaining 10 rounds. This belief was elicited after the end of the first 20 rounds but before the composition of the postmerger firm was determined. Therefore, subjects had to base their expectation on the performance histories of the two premerger firms (subjects had access to the full history of completion times for the other firm as well as for their own). Subjects were told that the one subject who was left out of the postmerger firm would be rewarded for a correct prediction ( $\$ 10$ for being within 3 seconds of the actual average time and $\$ 4$ for being within 20 seconds). This was done to obtain a measure of the expected performance of the postmerger firm (similar to analysts' predictions) that may be biased if the potential culture conflict is not taken into account. 
Finally, subjects were also asked to complete several questionnaires at two different points in the experiment. The first questionnaire was immediately administered after the first 20 rounds, and asked subjects about the competence of the other subject in their firm (relative to other comparable students) and about the difficulty of the task. The second questionnaire was administered at the end of the experiments and asked similar questions about the other two employees in the merged firm.

In addition to the above sessions (of which we conducted 11), we also conducted 5 control sessions in which three-person groups (with one manager and two employees) performed the task for 20 rounds. These sessions serve as a comparison for the merged firms to test whether any differences in performance, pre- and postmerger, simply result from differences in performing the task with two instead of one employee.

Participants were students at the California Institure of Technology (Caltech) and Carnegie Mellon University (CMU) who were recruited from a list of people interested in participating in experiments. They were paid their earnings in cash at the conclusion of the experiment.

\section{Results}

This task creates simple "cultures" by requiring subjects to develop conversational norms to quickly refer to pictures. For instance, one pair of subjects began by referring to a particular picture as: "The one with three people: two men and one woman. The woman is sitting on the left. They're all looking at two computers that look like they have some PowerPoint graphs or charts. The two men are wearing ties and the woman has short, blond hair. One guy is pointing at one of the charts." After several rounds, this group's description of this picture was condensed to simply "PowerPoint."

Of course, these cultures can be extremely idiosyncratic, because they seize on distinctive shards of language developed in the long initial descriptions, or on shared experience within the pair, which is unlikely to be common to outside observers. This process results in sound bite descriptions that often focus on different aspects of the pictures in different pairs. For instance, the picture called "PowerPoint" by one group was called "Woman sitting, smiling" and "Guy hunching" by other groups. It is unlikely that members of one group would be immediately aware of which picture the other group was referring to by hearing their description.

In another example, one pair of student subjects began referring to a picture as "Uday Rao," because a person in the picture resembled a professor by that name who taught a class both students were taking. The idiosyncrasy enables a pair to become extremely efficient (cf. Arrow 1974), but idiosyncrasy also makes it more difficult to combine two pairs and create a common language. In the example, when the new employee was brought in, he had no idea who Uday Rao is, so it took extra time to backtrack and find a different way to describe that picture (and wasted the time of the old employees did know Uday Rao).

Figure 2 shows the series of completion times across periods. The first thing to notice is that the completion times are initially high: the average completion time in the first round is 249 seconds. The time it takes to complete the task decreases as groups develop concise ways to refer to the pictures. By the 10th round, the average completion time is 95 seconds and this goes down to 48 seconds by the 20th round. Therefore, while the task is initially somewhat difficult because groups lack a common way to refer to the pictures, they become much quicker once they develop a shared language. ${ }^{11}$

The average completion time increases once the groups are merged-from 48 seconds in round 20 to 130 seconds in the first postmerger round (pooling both postmerger employees). This mean change in completion times of 82 is significantly different from 0 at the $p<0.001$ level $\left(t_{10}=8.00\right)$. While subsequently the amount of time it takes to complete the task decreases with experience, this improvement takes several rounds. The average completion time for rounds 15-20 in Figure 2 (last 5 premerger rounds) is 52 seconds. The merged group is (on average) never able to complete the task in this amount of time or

${ }^{11}$ The time series resembles other types of organizational learning curves (see Argote 1996). 
WEBER AND CAMERER

Cultural Conflict and Merger Failure

Figure 2 Average Completion Times (11 Merger Sessions)

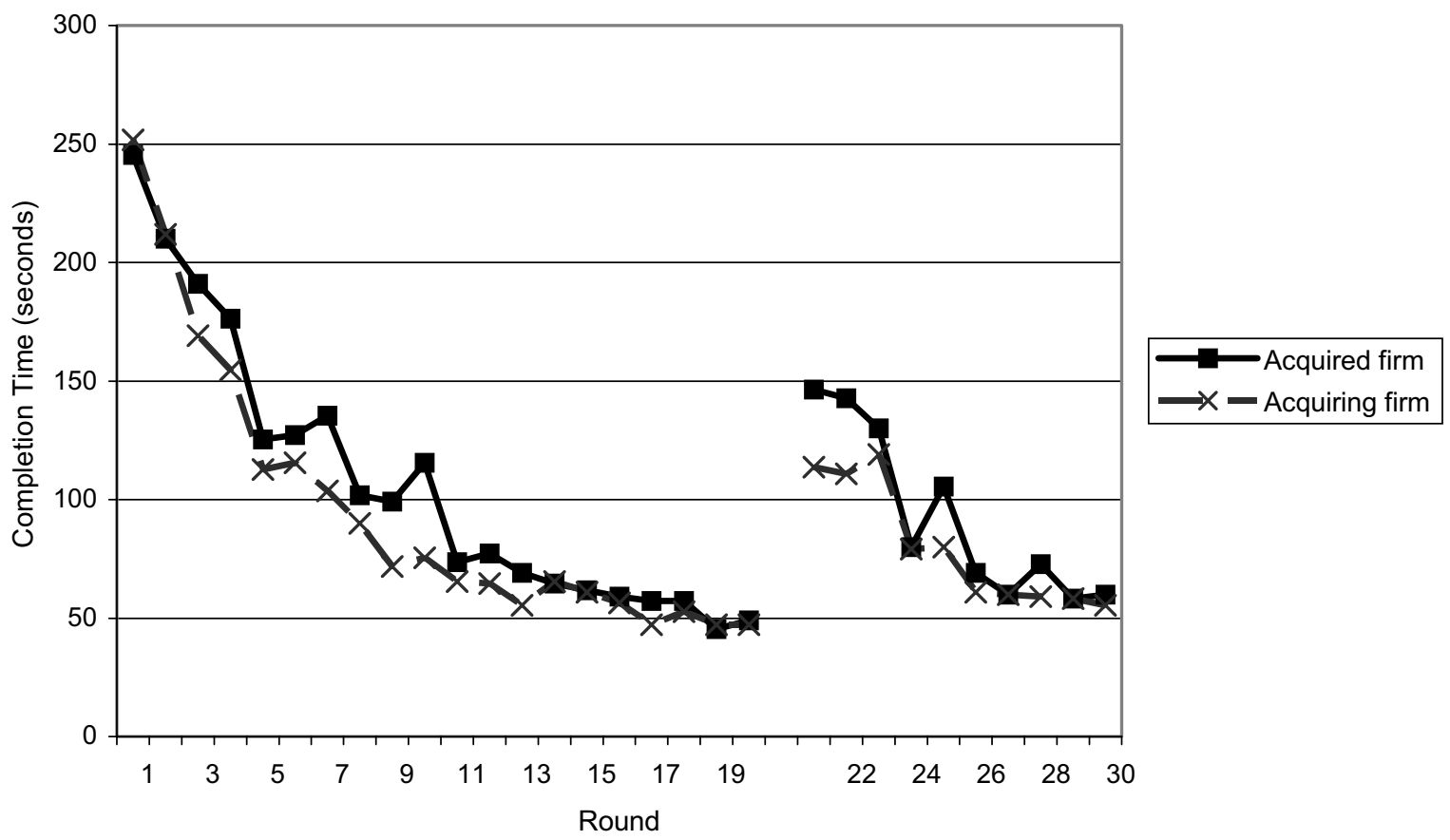

less in any of the 10 postmerger rounds. The average completion time for the first 5 rounds after the merger is 111 seconds, and this average difference of 59 is significantly different from $0\left(p<0.001, t_{10}=\right.$ 6.19). In rounds $6-10$ after the merger, the average completion time is 61 seconds, and the average difference between these rounds and the last 5 premerger rounds of 9 seconds is significant at the $p<0.05$ level in a one-tailed test $\left(t_{10}=1.83\right)$. Therefore, using the session/merger as the unit of analysis, we see that the performance of the postmerger firm is significantly lower than that of the two premerger firms.

It is worth noting that-even immediately after the merger-the merged group performs better than groups with no experience (at the beginning of the experiment). Therefore, there is some successful integration of cultures between the two groups, and the merged groups perform better than groups of subjects with no experience whatsoever. However, the clear and significant increase in completion time indicates that the cultural integration process does present problems that lead to, at least, temporary decreases in performance, relative to performance immediately before the merger.
Notice also that while the initial increase in completion times is not the same for the acquired and acquiring employees, the merger, in fact, slows down both employees. In the first three rounds following the merger, the new employees' average completion times are 146, 143, and 130, while the familiar employees' average times are 114, 111, and 119. Following the third round, the completion times are roughly equal for both employees (80 and 79.1 for the acquired and acquiring employee, respectively, in the fourth round). The difference in completion times is marginally significant for the first postmerger round $\left(t_{20}=1.58, p<0.1\right.$, one tailed), but not for later rounds.

One possible explanation of the above results is that they simply represent two-person versus three-person group-size effect. That is, it is possible that completion time increases postmerger not because of any differences in language, but, instead, simply because the larger group size makes the manager's job more difficult. Because the above experiment confounds the merger event with such a possible group-size effect, we conducted control sessions in which three-person groups played the task for 20 rounds. The task in these sessions was exactly the same. However, in 
these sessions, subjects started off in groups of three, with one manager and two employees, and no mention was made of a merger. These three-person groups performed the task for 20 rounds and were then paid their earnings.

There were a total of 5 control sessions. ${ }^{12}$ Figure 3 reports the average completion time for the 5 control sessions, along with the average time for the first 20 rounds of the merger sessions (the dashed line in Figure 3 is the average of the 2 lines over the first 20 periods in Figure 2). As is clear from examining the figure, there is no difference in completion times between the two group sizes. Therefore, the difference in pre- and postmerger completion times in the merger sessions is unlikely to be due to a pure group-size effect.

Overall, our results show that merged groups do considerably worse on average than the two separate premerger groups were doing immediately before the merger. This is especially true in the first five periods after the merger, but also continues into later rounds as well. In fact, the outcomes are quite striking: in all 11 sessions, the average completion times increased from the last 5 rounds before the merger to the first 5 rounds after the merger $(p<0.01$ in a binomial test). Because the control sessions indicate no pure group-size effect, language problems create inefficiency in the merged groups even when both firms were efficiently performing the task in the rounds leading up to the merger.

Comparing the completion times before and after the merger reveals that both employees are performing worse after the merger. Therefore, if we are concerned only with employee productivity, the merger clearly negatively affects performance. However, in most real-world mergers, there are benefits from merging that may outweigh the costs such as decreased productivity. In our laboratory "firms," one such benefit is the reduction of the total number of employees from 4 to 3 (by pruning the extra manager). Thus far, our experiments and analysis have focused only on simple mergers without any synergies, and ignoring any cost savings. As a result,

\footnotetext{
${ }^{12}$ A sixth control session was excluded because one of the subjects (the manager) had previously participated in one of the "merger" sessions. The subject denied having participated in the experiment, but this was later confirmed by examining records.
}

one possible criticism of our interpretation of the above results has to do with the way in which the merger occurs in our experiments. ${ }^{13}$ Suppose that each employee of the two original firms is paid a fixed wage. Then, the benefit of the merger is that it saves one-fourth of the total labor costs because the merged firm requires only 3 , instead of 4 , employees to produce the same "output" as before (two sets of solved pictures). Therefore, to truly measure a decline in performance, our analysis needs to take into account these decreased costs. As a result, the premerger firms need to be at least $25 \%$ faster for it to truly represent worse performance by the merged firm.

To address this concern, we turn to the data. ${ }^{14}$ As we previously noted, the saved labor costs result in a decrease in total wages of $25 \%$. Therefore, the premerger firm must be $25 \%$ faster to be performing better. When we do a comparison of the pre- and postmerger rounds using this standard, we see that the merged firm needs an average completion time of 69 seconds (instead of 52) to match the performancewhen taking into account the cost savings-of the premerger firm during the last 5 rounds. Comparing this to the average completion times in each postmerger round, we see that the merged firm still does considerably worse for the first 5 rounds, but overtakes the original firms' performance in round 6 . However, there is still a substantial, and significant, decrease in performance in the rounds following the merger, indicating that even by this higher standard, we still find a decrease in performance following the merger.

\footnotetext{
${ }^{13}$ An anonymous reviewer pointed this out to us.

${ }^{14}$ Another possible response to this concern has to do with the way the experiments should be interpreted. We designed the experiments to include the minimal key elements necessary to capture the real-world phenomenon of cultural conflict. One of the goals of the experiment was to capture possible decreases in performance by both "familiar" and "unfamiliar" employees due to cultural and language conflict. As a result, it is sufficient for our experimental "firms" to include one of each, and show that this decrease in performance occurs. In real-world firms in which there are many more employees, the decrease in performance is likely to have a significantly greater impact.
} 
WEBER AND CAMERER

Cultural Conflict and Merger Failure

Figure 3 Average Completion Time (5 Control Sessions, 11 Merger Sessions)

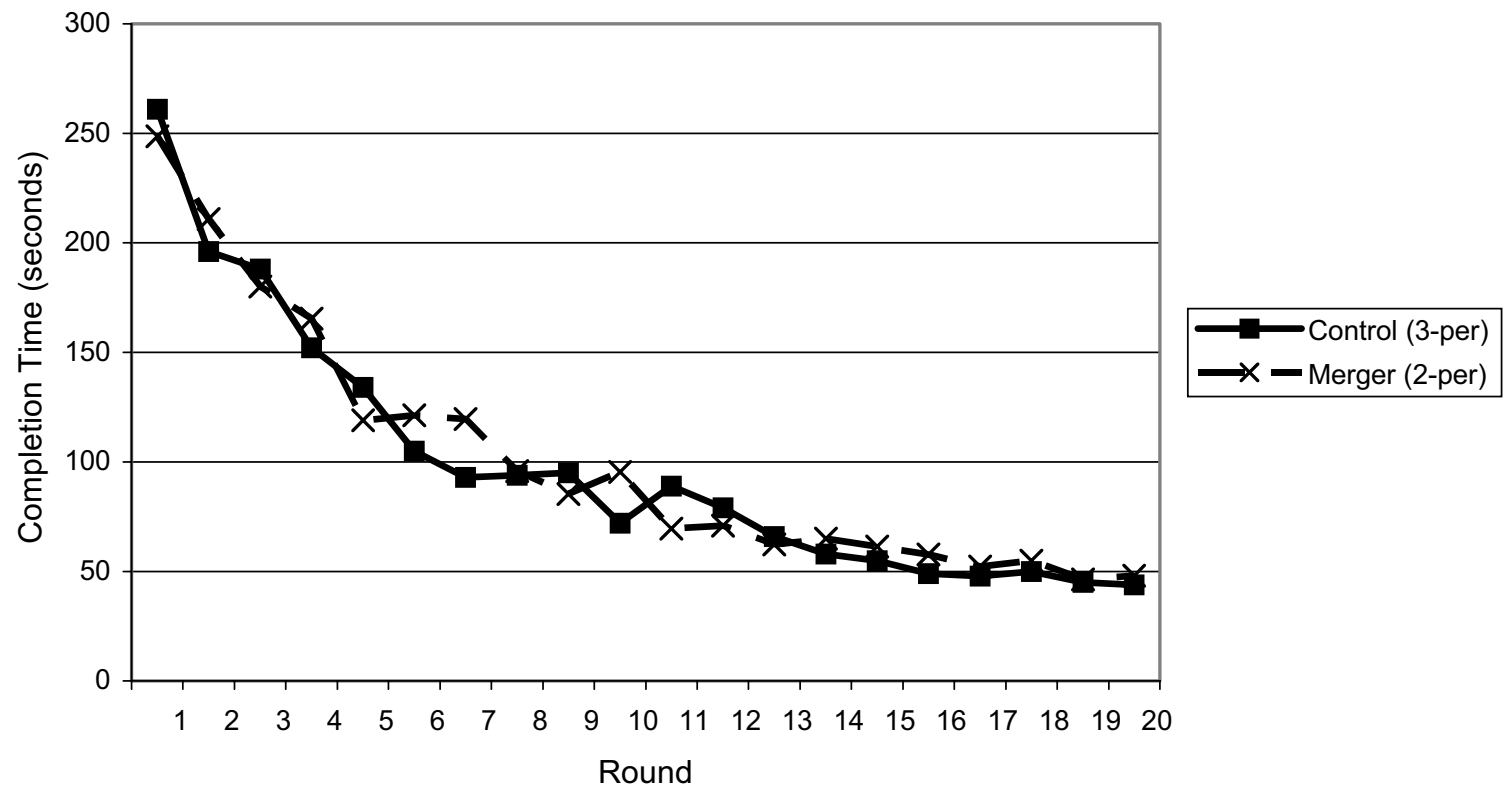

We also collected subjects' estimates of the postmerger completion times. ${ }^{15}$ Subjects could receive a bonus if they accurately predicted the average completion time in their session. The average completion time during the last 10 (postmerger) rounds in these sessions was 86 seconds, while the average estimate was 69 seconds, indicating that subjects were, on average, overly optimistic about the amount of time it would take the merged group to complete the task. ${ }^{16}$ Comparing the average completion time during the 10 rounds in each session with the average guess for that session results in a significant difference $\left(t_{10}=2.60, p<0.02\right.$, one tailed). Looking at individual predictions, of 43 subjects' estimates, 33 (77\%) were overly optimistic, while only $10(23 \%)$

\footnotetext{
${ }^{15}$ One subject's prediction was excluded from the analysis because this subject wrote down 800 seconds (the highest possible completion time is 300 seconds).

${ }^{16}$ Research by psychologists has shown that people generally underestimate the time it will take to complete tasks (e.g., Buehler et al. 1994). However, this bias is found when estimates concern unfamiliar tasks and is eliminated when subjects use past experience in informing their estimates. In our case, subjects have both recently participated in 20 rounds of the task and are given the full list of previous completion times when making their estimates (see Byram 1997).
}

were pessimistic about the merged group's performance, and this difference is significant in a sign test using the normal approximation of the binomial distribution ( $p<0.001, z=3.35)$. Therefore, we find clear evidence that subjects underanticipated the cultural conflict and tended to "overvalue" the merger.

Another result from these experiments has to do with conflict between members of the acquiring "firm" and the new employee. One possible source of merger failure is exactly this type of conflict (Buono et al. 1985). The first piece of evidence that this occurred in our experiments is anecdotal. In some sessions, there was tension and hostility between the manager of the merged firm and the new employee. This usually resulted from the manager having to provide longer and more detailed explanations to the new employee than to the familiar employee. In some cases, these longer explanations still did not work because the two subjects were focusing on different aspects of pictures. For instance, in one case, the manager was trying to describe a picture that subjects in the acquiring firm had come to refer to as "coffee mugs" because of their presence on a table at the front of the picture. The other group had referred to this picture as "cupboard in back." The manager and new employee spent close to a minute trying to jointly 
identify this picture. During this time, the manager would repeat some aspects of the picture (such as the number of people) and then refer to the coffee mugs on the table. The delay was mainly due to the employee taking awhile to identify a likely picture (there were other pictures with coffee mugs), but even after she had the correct picture, she tried to verify this by asking if the picture had a cupboard in the back. Even though it did, the manager (annoyed at the delay by now) replied, "I don't know, just look for the coffee mugs!" leading to a longer delay before the employee could be sure she was talking about the same picture. In another case, an acquired employee angrily interrupted a manager: "Stop telling me what they're wearing and just tell me how many people are in the picture!" This type of mild hostility resulting from different perspectives occurred in a few cases in the experiment.

A more precise measure of the conflict can be seen in responses to questionnaires that were administered both immediately after the first (premerger) part of the experiment and at the end of the 10 postmerger rounds. The questionnaire included items asking people to evaluate whether the other participants are "better or worse at this task than the average CMU (or Caltech) student would be?" Of particular interest, subjects who were acquired in the merger gave the premerger manager they worked with an average rating of 6.7 on a 9-point scale. These same employees, however, gave the new manager only a 4.8 rating. The average change in ratings of 1.9 is significantly different from $0\left(p<0.05, t_{10}=2.28\right)$. Of 11 acquired employees, 7 rated the new manager as worse, while only 3 rated the new manager as better (this difference is not significant in a sign test).

Similarly, both employees of the acquired firm rated the new employee as worse than the employee they were more familiar with. In postmerger ratings, managers rated the familiar employee (average rating $=$ 6.4) as better than the new employee (average rating = 5.5), though this difference is not significant. Of 11 managers, 6 rated the familiar employee as more competent, while 3 rated the new employee as more competent (also not significant). The employees of the acquiring firm gave the manager who they were familiar with higher average ratings (7.3) than they did the new employee (6.2), and this difference is significant $\left(p<0.01, t_{10}=3.83\right)$. In fact, of 11 employees of the acquiring firm, 8 gave the manager higher ratings while none gave the new employee higher ratings $(p<0.01$ in a sign test).

This is in spite of the fact that both employees of the acquiring firm recognized that the new employee's job was more difficult. In a postmerger question asking how easy (9) or difficult (1) the task was for other subjects, the acquiring manager and employee rated the new employee's task as more difficult (4.1 and 4.2 , respectively) than they did for the other subject who they were familiar with (6.9 and 5.0). Therefore, in spite of recognizing the difficulty with learning another firm's "culture," subjects still place blame on members of the other premerger firm and attribute the postmerger difficulty to their lack of competence. These results are consistent with the attributions literature in which people overassign responsibility for outcomes to others' personal traits, relative to situational variables (Weber et al. 2001, Ross and Nisbett 1991). While the simple questions used here do not constitute a behavioral measure, Weber et al. (2001) show that a similar result holds when subjects take actions that determine monetary incentives.

\section{Conclusion}

The idea guiding this research is that failures to coordinate activity, based on cultural conflict, contribute to the widespread failure of corporate mergers. Furthermore, we suggest that the likelihood of cultural conflict and coordination failures is underestimated, which explains why firms enter into so many mergers that are doomed in the first place. Our experiments support both hypotheses: Differences in culture between our laboratory firms lead to consistent decreased performance for both employees after the merger, and subjects underpredicted the extent of this decrease. In addition, we also find evidence of conflict and mistaken blame arising from the differences in culture, pointing to a possible source for the highturnover rate following real mergers.

Future work might deal with omissions from these experiments, and might build on what we have learned from this study, while including more realistic aspects of real-world mergers. For instance, a 
likely omission is conflict of interest or perspective. For example, suppose one pair represents "human resources" and is trained to describe pictures in terms of their human features; another represents "technology" and talks in terms of machinery. It is possible that this specialization in function and skill leads to a high degree of specialization in language-and a blindness toward the language of others, which makes postmerger communication even more difficult. This is consistent with work by Dearborn and Simon (1958) and Dougherty (1992), indicating that specialists may have a difficult time taking the perspective of people in other areas. We would like to incorporate other ideas (some of these would involve adjusting the paradigm to allow for larger "firms").

Decayed Organizational Memory and the Evolution of Culture. In our experiments, the retained manager remembers how difficult it was to create language initially (in the premerger phase). This may give him or her extra patience or skill in creating a new hybrid language (or explaining the old language) when the merger occurs. A twist on our design is to bring in additional subjects only during the last few trials of the premerger phase, when the language is brief and working well. They may be more prone to overestimate how easy the postmerger transition will be, because they have not experienced the worst part of the early premerger learning. Another possibility is that bringing in new people to replace old employees may maintain the organization's culture, but make it especially susceptible to ignoring how difficult it is to develop a language.

We are also interested in exploring how organizational culture may evolve or change as new people are brought into the organization to replace existing members. In particular, is it possible for the organizational culture to remain intact even once the original employees have all been replaced (cf. Zucker 1977)? Another issue is how the development of culture is affected by the patterns of interaction between members of the organization.

Turnover and Blame. The questionnaires we administered suggest a typical pattern of blame consistent with research on attribution errors: Employees of the acquired firm blamed the new employee, and new employees blamed the managers, for poor postmerger performance. It would, therefore, be interesting to allow managers to terminate employees, and allow employees to quit. One hypothesis is that they would terminate and quit too hastily, not anticipating how much easier communication becomes with practice. Hasty termination could backfire for managers if the new employees who replace the fired ones take even longer to learn the new language. On the other hand, it is conceivable that the replacements would do better learning the manager's language because they start tabula rasa.

Solutions. If we can produce reliable problems with postmerger integration, then we can also test possible solutions. For example, in the experiments, a couple of subjects asked, "Can we just have a few minutes to talk about this?" before beginning the merger phase of the experiment. A consultant at McKinsey told us that his prescription for improving postmerger integration is to create a new task on which employees from both the acquiring and acquired firm work together. By using a new task, the employees are inhibited from using the full extent of their culture that is familiar from old tasks, and are able to compromise on a new shared way of doing things. The effectiveness of prescriptions like these could be easily tested in experiments.

While the above all point to additional work that will, hopefully, produce additional insights into how mergers and culture operate in the real world, our main point in this paper was to use a simple experimental procedure to make an important point. By recreating a simple form of culture in the laboratory encompassing many key aspects of real-world organizational culture, we provided a clear situation in which merger failure is driven by differences in this culture.

\section{Acknowledgments}

The authors thank participants at the 2000 Behavioral Decision Research in Management meetings in Tucson, Arizona; the 2000 Economic Science Association meetings in New York, New York; the 2001 Carnegie-Bosch conference on Managing Knowledge in Organizations, in Pittsburgh, Pennsylvania; the 2002 Conference on Behavioral Learning and Bounded Rationality in Aix-en-Provence, France; and seminar participants at Carnegie 
Mellon University, Harvard Business School, and the University of Pittsburgh for helpful comments and suggestions. This research was supported by National Science Foundation Grant \#SES-0095570. Thanks also to Dan Clendenning and Jason Dana for research assistance. This work has benefited greatly from the authors' discussions with Linda Argote, Linda Babcock, Paul Fischbeck. Chip Heath, Herb Simon, and George Loewenstein, and from the three anonymous reviewers.

\section{References}

Argote, L. 1996. Organizational learning curves: Persistence, transfer and turnover. Internat. J. Tech. Management 11 759-769.

Arrow, K. A. 1974. The Limits of Organization. W. W. Norton \& Company, New York.

Barley, S. R. 1983. Semiotics and the study of occupational and organizational cultures. Admin. Sci. Quart. 28 393-413.

Beuhler, R., D. Griffin, M. Ross. 1994. Exploring the planning fallacy-Why people underestimate their task completion times. J. Personality Soc. Psych. 67(3) 366-381.

Blume, A., D. V. DeJong, Y. G. Kim, G. B. Sprinkle. 1998. Experimental evidence on the evolution of meaning of messages in sender-receiver games. Amer. Econom. Rev. 88(5) 1323-1340.

Buono, A. F., J. L. Bowditch, J. W. Lewis. 1985. When cultures collide: The anatomy of a merger. Human Relations 38 477-500.

Byram, S. J. 1997. Cognitive and motivational factors influencing time prediction. J. Experiment. Psych.-Appl. 3(3) 216-239.

Chatterjee, S., M. H. Lubatkin, D. M. Schweiger, Y. Weber. 1992. Cultural differences and shareholder value in related mergers: Linking equity and human capital. Strategic Management J. 13 319-334.

Clark, H. H., D. Wilkes-Gibbs. 1986. Referring as a collaborative process. Cognition 22(1) 1-39.

CNN/Money. 2001. Daimler to repair Chrysler. CNN/Money online http://www.money.cnn.com February 26.

CNN/Money. 2001. Chrysler to cut 26,000 jobs. CNN/Money online http://www.money.cnn.com February 29.

Cook. W. J. 1998. Maximum merger. U.S. News \& World Rep. May 18 124(19) 45-47.

Cremer, J. 1993. Corporate culture and shared knowledge. Indust. Corporate Change 2(3) 351-386.

Dearborn, D. C., H. A. Simon. 1958. Selective perception: A note on the departmental identification of executives. Sociometry 21 140-144.

Dougherty, D. 1992. Interpretive barriers to successful product innovation in large firms. Organ. Sci. 3(2) 179-202.

Fussell, S. R., R. M. Krauss. 1989. The effects of intended audience on message production and comprehension: Reference in a common ground framework. J. Experiment. Soc. Psych. 25 203-219.

Harrison, J. S., M. A. Hitt, R. E. Hoskisson, R. D. Ireland. 1991. Synergies and post-acquisition performance: Differences versus similarities in resource allocations. J. Management 17(1) 173-190.
Hermalin, B. E. 2001. Economics and corporate culture. S. Cooper, S. Cartwright, P. C. Early, eds. Handbook of Organizational Culture and Climate. John Wiley and Sons, Chichester, U.K.

Hofstede, G. 1984. Cultures Consequences: International Differences in Work-Related Values. Sage Publications, Beverly Hills, CA.

, B. Neuijen, D. D. Ohayv, G. Sanders. 1990. Measuring organizational cultures: A qualitative and quantitative study across twenty cases. Admin. Sci. Quart. 35 286-316.

Jubak, J. 2000. Jubak's journal: What's AOL worth now? MSN/ Money on-line http://www.moneycentral.com January 18.

Knez, M., C. F. Camerer. 1994. Creating expectational assets in the laboratory: Coordination in weakest-link games. Strategic Management J. 15 101-119.

_ -2000 . Increasing cooperation in social dilemmas by establishing a precedent of efficiency in coordination games. Organ. Behavior Human Decision Processes 82(2) 194-216.

Krauss, R. M., P. S. Vivekanathan, S. Weinheimer. 1968. "Inner speech" and "external speech." J. Personality Soc. Psych. 9295 300.

Kreps, D. M. 1990. Corporate culture and economic theory. Perspectives on Positive Political Economy. J. E. Alt, K. A. Shepsle, eds. Cambridge University Press, Cambridge, U.K.

Larsson, R., S. Finkelstein. 1999. Inegrating strategic, organizational, and human resource perspectives on mergers and acquisitions: A case survey of synergy realization. Organ. Sci. 10(1) 1-26.

Lazear, E. P. 1999. Culture and language. J. Political Econom. 107(6) 95-126.

Marcoulides, G. A., R. H. Heck. 1993. Organizational culture and performance: Proposing and testing a model. Organ. Sci. 4(2) 209-225.

McGuckin, R., S. V. Nguyen, A. P. Reznek. 1995. The impact of ownership change on employment, wages, and labor productivity in U.S. manufacturing 1977-1987. Working paper, CES 95-8, The Center for Economic Studies, U.S. Bureau of the Census, Upper Marlboro, MD.

Murray, M., N. Deogun, N. Wingfield. 2000. Can Time Warner click with AOL? Here are eight things to watch. The Wall Street Journal (January 14) A1.

O'Reilly, C. A., III, J. Chatman, D. F. Caldwell. 1991. People and organizational culture: A profile comparison approach to assessing person-organization fit. Acad. Management J. 34(3) 487-516.

Ravenscraft, D. J., F. M. Scherer. 1987. Life after takeover. J. Indust. Econom. 36(2) 147-156.

_ 1 - 1989. The profitability of mergers. Internat. J. Indust. Organ. 7(1) 101-116.

Roll, R. 1986. The hubris hypothesis of corporate takeovers. J. Bus. 59(2) 197-216.

Ross, L., R. E. Nisbett. 1991. The Person and the Situation. McGrawHill, New York.

Rousseau, D. 1990. Assessing organizational culture: The case for multiple methods. B. Schneider, ed. Climate and Culture. JosseyBass, San Francisco, CA.

Schall, M. S. 1983. A communication-rules approach to organizational culture. Admin. Sci. Quart. 28 557-581. 
WEBER AND CAMERER

Cultural Conflict and Merger Failure

Schein, E. H. 1983. The role of the founder in creating organizational culture. Organ. Dynam. 12 13-28.

- 1990. Organizational culture. Amer. Psych. 45(2) 109-119.

- 1996. Culture: The missing concept in organization studies. Admin. Sci. Quart. 41(2) 229-240.

Schober, M. F., H. H. Clark. 1989. Understanding by addressees and overhearers. Cognitive Psych. 21(2) 211-232.

Shanley, M. T., M. E. Correa. 1992. The agreement between top management teams and expectations for post acquisition performance. Strategic Management J. 13 245-266.

Shelton, L. M. 1988. Strategic business fits and corporate acquisition: Empirical evidence. Strategic Management J. 9 279-287.

Singh, H., C. A. Montgomery. 1987. Corporate acquisition strategies and economic performance. Strategic Management J. 8 377-386.

Vlasic, B., B. Stertz. 2000. Taken for a Ride: How Daimler-Benz Drove Off with Chrysler. William Morrow \& Co., New York.
Walsh, J. P. 1988. Top management turnover following mergers and acquisitions. Strategic Management J. 9 173-183.

- J. W. Ellwood. 1991. Mergers, acquisitions, and the pruning of managerial deadwood. Strategic Management J. 12 201-217.

Weber, R. A. 2000. Organizational growth and coordination problems: An experimental study. Working paper, Department of Social and Decision Sciences, Carnegie Mellon University, Pittsburgh, PA.

_ C. F. Camerer, Y. Rottenstreich, M. Knez. 2001. The illusion of leadership: Misattribution of cause in coordination games. Organ. Sci. 12(5) 582-598.

Wilkins, A. L., W. G. Ouchi. 1983. Efficient cultures: Exploring the relationship between culture and organizational performance. Admin. Sci. Quart. 28 468-481.

Zucker, L. 1977. The role of institutionalization in cultural persistence. Amer. Soc. Rev. 42 726-743.

Accepted by Linda Argote, Bill McEvily, and Ray Reagans; received March 1, 2001. This paper was with the authors 9 months for 2 revisions. 